\title{
Editorial Introduction to a Collection from the 2003 BSA Conference 'Social Futures: Desire, Excess and Waste' the Consumption and Waste Stream
}

\author{
Andrea Abbas, Steve Taylor, Tony Chapman, Dave Morland and Diane Nutt \\ University of Teesside
}

\author{
Sociological Research Online, Volume 10, Issue 2, \\ < http://unw. socresonline.org.uk/10/2/abbas. html> \\ doi:10.5153/sro. 1106
}

Received: 21 Jun 2005 Accepted: 21 May 2005 Published: 30 Jun 2005

\section{Introduction}

1.1 This is one of two collections of papers from the British Sociological Association (BSA) annual conference 2003 that we have put together for Sociological Research Online. In developing a title and theme for the 2003 conference we sought to encourage contributors to challenge and engage with contemporary political and media discourses, which since the election of the New Labour government in 1997, had tended to emphasise success, progress and freedom. We invited colleagues to write critical papers that used sociological theory to reflect on real-world problems and issues including the problems of global development, environmental issues, technological change and contemporary cultural experience. We also hoped to stimulate cross-disciplinary debate and wished authors to consider the position and the potential of sociology, in this respect. We devised five conference themes to reflect these interests: Belonging and Isolation; Consumption and Waste; Winners and Losers; Technological Dystopias; Escape Strategies; as well as submissions to the open stream. Over 120 papers were presented at the conference and there were two well attended and livelily debated plenary sessions, one by Beverley Skeggs (then at the University of Manchester) and one by George Ritzer (University of Maryland). Approximately 80 papers presented at the conference were submitted for consideration for publication in this and two other volumes. Two members of the panel read every paper and those presented here are among 19 papers, which were chosen to be included in publications from the conference. The papers were initially selected on the basis of quality and originality but as so papers many achieved the standards we set, we selected those papers which best fitted together and because they represented some of the key issues discussed at the conference. The papers in this collection are from the Consumption and Waste stream.

\section{The Consumption and Waste Stream}

2.1 Consumption is a concept and theme which has become a central preoccupation of many contemporary sociological theorists (e.g. Bauman, 1998a;Douglas and Isherwood, 1979;Forty, 1995;Lury, 1996;Miller, 1987; Ritzer, 1995, 1999; Warde, 1997). Sociological theorising relating to consumption has for some time been concerned with the themes suggested by the title of the conference as the, production, reproduction, use, and treatment of desire, excess and waste (e.g. Bourdieu, 1984; Beck, 1995; Veblen, 1925) have been situated very firmly as issues relating to Western consumer societies. The papers received for the consumption and waste stream engaged both theoretically and empirically with many areas of social life including: bodily experiences and embodiment; the supply and use of formerly publicly supplied goods and services; experiences of home; urban spaces; leisure; age-related experiences; political action; gender; class; ethnicity and our understanding of, and relationship with other cultures.

2.2 Bauman (1998a; 1998b) and others have suggested that "desire" is an essential part of any "consumer society" and sociologists of different theoretical persuasions have attempted to understand the nature and significance of individual and collective "desires" and how they are shaped and expressed in and through consumption (e.g. Baudrillard, 1996, 1998; Marcuse, 1964). Some of the papers included in this collection bring out the complex issues and contradictions involved in producing, stimulating and fulfilling "desires". The stimulation of desire has long been association with the experience of the city. Van der Land's case study of Rotterdam challenges claims that consumer experiences and attachment to cities is fleeting and depthless (Zukin, 1991). He suggests that developing city centres, to fulfil or increase their desirability to more affluent consumers can result in the new middle classes becoming attached to places even when they are incoming residents or living in suburban areas. He argues that if people have frequent and sufficiently intense consumption experiences within a city, the "city is acquired" and becomes "a place of one's own". Massey's paper based in Manchester, on the other hand, emphasises the downside of a similar process of city-centre development by bringing out the way that the redesigning of the city centre, following the 1996 IRA bombing, has displaced smaller traders to, less central parts of the city, and in some cases all together. Her data suggests that traders see the gentrification of consumption in the city centre as reducing 
the attractiveness of it for certain groups. Hence, together Van der Land and Massey's papers highlight some of the tensions or contradictions in developing "desirable" city centres. They also raise issues because as Low (2003) suggests space can be contested, dialogic and contradictory and as government economic, social and political agendas become further entwined with capitalism these become embedded in the architectural design of city centres and this influences who accesses city centres and how they are used.

2.3 Huizinga (1955) believed that the displays of abundance or excess involved in gift giving rituals were an important part of play that satisfied "the imperishable need" for people "to live in beauty" (p.63). The environmental effects of consuming in abundance have until recently largely taken place outside of the sociology of consumption (e.g. Yearly, 1991). However, with the proliferation of debates around "sustainability" and "green consumerism" sociologists working in the area of consumption have begun to engage more fully with these debates. Some of this work has looked at the way that waste and wastefulness are produced and defined through daily practice and how these impact upon the way people use goods and produce and manage waste (e.g. Hetherington, 2003). The sustainable production, management and use of water are something that unites two papers in this collection, which approach this issue in very different ways. Sherlock et al. discuss how sociological theories and discourses can be utilised in practice to inform policy and understandings of how to produce more sustainable water practices. Hand et al's paper describes, theorises and analyses the growth in popularity of the use of the power shower, a resource heavy mode of washing. Although their paper is exploring the increased use of the power shower, as they point out, understanding "the relation between the material, the conventional and the temporal as configured through practice" could help develop ideas and policies based upon consideration of the specific difficulties or ease associated with changing peoples' behaviour.

2.4 The main title of the conference "social futures" asked contributors to reflect upon and consider the possible contribution of sociology to the global society of the future. All the papers in this collection in one way or another address the issue of describing or facilitating a changing "social future", with some scenarios being more bleak than others. Sustainability and the development of city centres have obvious contributions to make to urban planning. Hand et al's paper describes how currently entrenched social processes suggest bleak futures in terms of inequality and sustainability respectively. Whilst Sherlock et al also describe the entrenched practices of organisations charged with facilitating sustainable development which contribute to continued excessive use of water: they also suggest ways in which sociology might promote change. Nick Stevenson's paper attempts to envision a better more sustainable future. He seeks to develop and explore the notion of "cultural citizenship" as a way of encouraging and stimulating changing attitudes and behaviour.

\section{The Papers}

3.1 The first two papers are on theme of consumption and city centre development which has been a growing and important area of literature for some time (e.g Low, 2000; Zukin, 1991, 1995). It is also of continuing importance in policy terms as it is the type of development inherent in the New Labour Government's regeneration agenda (e.g. Cultural Strategies) and which have been a critical focus as cities vie for titles such as "City of Culture". Van der Land's paper "Urban consumption and feelings of attachment of Rotterdam's new middle class" discusses the topic of whether gentrification results in cities being emptied of meaning and lessening of what Low (2000) refers to as place attachment. His paper is based on "The Urban Ties Survey" of Rotterdam (which surveyed 279 highly qualified professionals) and qualitative interviews with a sub-sample of the questionnaire respondents. After exploring some of the literature in this area that has suggested that city-centre development is likely to lead to an increasing lack of meaning and attachment through the commercialisation of experiences and space he describes the redevelopment and cultural regeneration of Rotterdam. Van der Land demonstrates how different sectors of the new middle classes are associated with different cultural and leisure activities with some such as the producer sector and cultural sector workers being more frequent participants and some being more associated with particular activities than others. The paper also demonstrates how occupation interrelates with age and gender, for example cultural workers visit leisure and cultural events more frequently at an older age than other groups. However, perhaps the most important findings relate to the psychological attachment (indicated by frequency of visits and reported feelings about the city) that Van der Land identifies and his suggestion that consumption experiences themselves might stimulate deeper feelings which contribute to place attachment.

3.2 In her paper "The Gentrification of Consumption: A View from Manchester", Massey uses the concept of gentrification to explore how the unified economic interests of developers and the state, came together in the context of the redevelopment of Manchester City Centre after the 1996 IRA bomb. Her empirical study brings out the impact gentrification had on traders and shoppers using the city centre. The focus is on one small area of the city where a space formerly populated by the more economically marginal (the Corn 
Exchange, now renamed 'The Triangle') become an upmarket shopping and pub/restaurant arena. She outlines how the winning of the redevelopment contract depends on the way that developers can blend and link the remaining city landscape whilst attracting companies who sought to invest in Manchester. This means trying to draw those with the most money to use the city centre. Massey suggests that redevelopment became part of Manchester becoming re-branded to shed its post-industrial reputation. The Corn Exchange with its market stalls and less affluent owners and clientele were displaced out and shops selling expensive designer goods designed in. Massey suggests that traders and local people had an inability to resist and although people appreciated certain aspects of the architecture they believed that local entrepreneurship had been designed out of the city centre. The paper adds to an increasing body of work on the impact of redevelopment on British cities (e.g. Chatterton and Hollands, 2003).

3.3 The next two papers both have the supply and use of water as empirically central. Sherlock, Kirk and Reeves paper "Sociology, Science and Sustainability: Developing Relationships in Scotland", describes how their ESRC funded project ended up demonstrating the practical use of sociological concepts and ideas relevant to sustainability in relation to water supply and use. Their project began as pure research which aimed to investigating the "role of disciplinary interactions on the development of environmental regulations" with a specific focus on "diffuse pollution". However, the institution they worked with, the Scottish Environment Protection Agency (SEPA) were attempting to implement the European Water Framework Directive (WFD) and called upon the expertise of the sociologist/researcher. Sherlock et al suggest that the sociological background of the researcher was helpful to SEPA. For example, they provided concepts to help think about "the context of sustainable water use". The biophysical approach, which dominated the practices of the agency, tended to focus on environmentally friendly disposal. Additionally, the sociologists emphasised the importance of participatory decision making by utilising the concept of the consumer-citizen. The authors describe the policy context in which more holistic approaches to sustainability are outlined and there is a rise in the desirability but not the practice of interdisciplinarity. They also highlight the difficulties of working with other disciplinary based practitioners who often do not understand the terms employed by national and international policy makers, for example, they claimed that they did not know what "the social use of water" meant. In describing the contribution the sociologistlresearcher made to the process and the contexts in which useful interventions could be made they also acknowledge that current organizational practices and structures inhibit interdisciplinary collaboration in practice.

3.4 Hand, Shove and Southerton's paper "Explaining showering: a discussion of the material, conventional, and temporal dimensions of practice" describes three "histories" associated with the developments in showering which have led to, and are projected to further fuel, a massive increase in water consumption nationally. The first narrative describes technological developments, such as the widespread provision of domestic hot water and developments in showering equipment, which are seen as important but not necessary or sufficient conditions leading to the widespread use of the power shower. The second story locates the developments of showering within an understanding of the cultural history of the body. In this way the authors demonstrate how showering practices have altered, for example, from communal to individualised practices according to historically specific understandings of the body and the purpose of showering. Hence, they suggest that the private but family orientated cubicles with room for one or a few family members, and the power shower mode of water delivery, need to be understood in terms of how the body is configured within a given historical period. The final history is about developments in temporal organisation of social life. The rise in the popularity of showering, it is suggested, needs to be understood in the context of increasing concern time as a scarce and valuable commodity and the configuration of the shower as something that can help deal with this. Hand et al then go on to consider how these three histories can be related in the sense of: how they fit together; how configurations and relationships between the different elements change; and, how "daily showering has become obligatory". The paper then goes on to explore a theory of practice which suggests that the different elements (material, conventional and temporal) are made concrete through the daily actions of people who in theory can choose to shower or not, but whose actions are restricted or shaped by the material, conventional and temporal world around them which is variously open and closed with respect to change. Understanding the processes which shape actions, which are for example, environmentally destructive, should help us understand how to change them.

3.5 The final paper in this collection is "Cultural Citizenship, Visual Culture and Risk in a Consumer Society" is by Nick Stevenson. In this paper Stevenson applies the notion of cultural citizenship to ecological citizenship. He begins his argument by contextualising attempts to encourage ecologically ethical behaviour suggesting that efforts to encourage ecologically sustainable behaviour should not begin by setting such action in opposition to enjoyable consumer experiences. Neither, he suggests should such a project be authoritarian and based upon "control and surveillance of citizens". He suggests that a "cultural citizenship" model should be based on the self-limiting actions by people through a revived interest in democracy. He suggests that this can best be achieved through acknowledging and validating the 
obvious pleasures of consumption and by engaging people in negotiation about how this can be done in a sustainable way. Hence, he suggests it is important to "develop a politics of citizenship that neither retreats into a celebration of consumption or moralistic reaction." Next Stevenson draws upon Beck's (1992) work to discuss the paradoxical role of science in being the means by which ecological damage has been caused but also the method through which planetary harm is revealed. He suggests that while scientific reason and practice are tied to commercial interests they are not subject to public or democratic scrutiny. Also, that the individualisation of consumption leads to people attempting to individually buy themselves out of risks as opposed to any really tackling of ecological problems. Hence, he suggests that we need new space for public dialogue and representation of all groups. He then goes on to analyse the film "Safe" which he sees as representing and highlighting key ecological problems but also as demonstrating that popular culture, which incorporates the experiential dimensions of consumption, is not necessarily oppositional to ecological concerns but can actually help people address them and perhaps facilitate dialogic politics.

3.6 We think these five papers cover many pertinent issues facing society and sociology. We hope you enjoy reading them as much as we have.

\section{References}

BAUDRILLARD, J. (1996) The system of objects. London: Verso.

BAUDRILLARD, J. (1998) The consumer society: myths and structures . London: SAGE.

BAUMAN, Z. (1998a) Work, consumerism and the new poor. Buckingham: Open University Press.

BAUMAN, Z. (1998b) Globalization. Cambridge: Polity Press.

BECK, U. (1992) Risk Society: Towards a New Modernity. London: Sage.

BECK, U. (trans. by Amos Weisz) (1995) Ecological politics in an age of risk . Cambridge: Polity Press.

BOURDIEU, P. (trans. Richard Nice) (1984) Distinction: a social critique of the judgement of taste.

London: Routledge \& Kegan Paul.

CHATTERTON, P. AND HOLLANDS, R. (2003) Urban nightscapes : youth cultures, pleasure spaces and corporate power. London: Routledge.

DOUGLAS, M. AND ISHERWOOD, B. (1979) The world of goods: towards an anthropology of consumption. London: Allen Lane.

FORTY, A. (1995) Objects of desire: design and society since 1750. London: Thames and Hudson.

HETHERINGTON, K. (2001) Paper presented to BSA Consumption Study Group Day conference on Ethical Consumption, at the Open University, $9^{\text {th }}$ November 2001

HUIZINGA, J. (1955) Homo Ludens: a study of the play element in culture . London: Routledge.

LOW, S. M. (2003) On the Plaza: The politics of public space and culture. Texas: University of Texas Press.

LURY, C. (1996) Consumer Culture. New Brunswick, N.J: Rutgers University Press.

MARCUSE, H. (1964) One dimensional man: studies in the ideology of advanced industrial society . London: Routledge and Kegan Paul.

MILLER, D. (1987) Material culture and mass consumption. Oxford: Basil Blackwell.

RITZER, G. (1995) Expressing America: a critique of the global credit card society . London: Pine Forge Press.

RITZER, G. (1999) Enchanting a disenchanted world: revolutionizing the means of consumption , London: Pine Forge Press.

VEBLEN, T. (1925) The theory of the leisure class: an economic study of institutions . London: Allen \& Unwin.

WARDE, A. (1997) Consumption, food and taste: culinary antinomies and commodity culture . 
London: Sage.

ZUKIN, S. (1991) Landscapes of power: from Detroit to Disney World . Berkeley: University of California Press.

ZUKIN, S. (1995) The Cultures of Cities, Blackwell, London. 